\title{
A Role for the Surgeon-Scientist? What Does the "Evidence" Tell Us?
}

Can J Neurol Sci. 2013; 40: 450-452

\begin{abstract}
"Background": An article in this issue of the Canadian Journal of Neurological Sciences provides a platform for reviewing the role of surgeon-scientists in contemporary medical practice ${ }^{1}$. The article by Fady Girgis is entitled "Feasibility of a dual neurosurgeon-scientist career in Canada: a survey study". The method used to obtain the data was an electronic survey distributed to staff neurosurgeons and neurosurgery residents across Canada. Questions were designed to identify qualities that exemplified ideal neurosurgical practice in relation to research.
\end{abstract} A neurosurgeon-scientist was defined as a neurosurgeon that spends at least $50 \%$ of his or her time performing research or research-related activities. In the case of residents the designation was based on intended practice, rather than current practice. In the results section the author presents the data from 54 neurosurgeons/residents that completed the survey, 32 of whom were current or intended neurosurgeon-scientists. The discussion reviews emergent themes such as: 1. Collaboration in research $(85.2 \%$ of respondents felt that neurosurgeons who collaborate with basic scientists to conduct research are equally or more likely to obtain meaningful results compared to neurosurgeon-scientist conducting the same research); 2. The 'ideal' versus the 'real' neurosurgeon $(83.3 \%$ of respondents did not feel that conducting research in addition to clinical duties was needed to become an 'ideal' neurosurgeon); 3. Research training in neurosurgery ( $85.2 \%$ of respondents were in favor of academic centres employing purely clinical neurosurgeons alongside neurosurgeon-scientists, rather than hiring only neurosurgeon-scientists, though $77.8 \%$ of respondents reported feeling pressure to publish journal articles). The author concludes that it is possible to do good work in both neurosurgery and neuroscience simultaneously, but in reality it is very difficult to do so.

"Methods": The author of this editorial performed a PubMed search using the term 'surgeon-scientist'. The articles were reviewed in varying levels of depth according to the information provided in the title and/or abstract. Themes from the articles are reported and discussed using the spirit and the space limitations of an editorial.

"Results": The PubMed search revealed 163 articles containing the term 'surgeon-scientist' (term 'physicianscientist' identified 777 articles!). Survey of these 163 articles revealed: 1. Many articles that were tributes and/or obituaries to/for eminent surgeons (surgeon-scientists) including the general surgeon Beaumont ${ }^{2}$, the neurosurgeon Rasmussen ${ }^{3}$ and the plastic/transplant surgeon Murray ${ }^{4} ; 2$. Many articles that were editorials/opinion pieces/published addresses, including those by Nobel laureates ${ }^{5-7}$, presidents of academic surgical societies $^{8,9}$, presidents of scientific societies ${ }^{10-12}$, and editors of prominent journals ${ }^{13,14} ; 3$. A smaller number of articles that did gather some data around the topic (surveys/data base extraction), especially as related to training ${ }^{15,16}$ and funding ${ }^{17}$ of the surgeon- scientist. Therefore, the "evidence", as it were, consists mostly of opinion, albeit much of that coming from well respected and successful surgeons and scientists, including surgeon-scientists. Listed below are some of the more noteworthy quotes from some of the articles.

From The University in American Surgery by Francis D. Moore $^{18}$ and cited by Chiu ${ }^{19}$ :

"A surgical investigator is a bridge tender, channeling knowledge from biological science to the patient's bedside and back again. He traces his origin from both ends of the bridge. He is thus a bastard and is called this by everybody. Those at one end of the bridge say he is not a very good scientist, and those at the other say that he does not spend enough time in the operating room. If only he is willing to live with this abuse, he can continue to do his job effectively."

From The Surgeon-Scientist in a New Biomedical Research Era by George K. Gittes (former president of the Society of University Surgeons) $)^{8}$ :

"Why do we care about the decline of the physicianscientist, and the surgeon-scientist in particular? The physician-scientist represents the cornerstone of American academic medicine, and clearly embodies what makes it great. Physician-scientists are essentially the only individuals who can facilitate flow of intellectual material from bedside to bench."

However, also from Gittes, in the same article ${ }^{8}$ :

"If we accept that increasing complexity represents the natural evolution of both basic science and clinical medicine, together with the burden of decreasing professional reimbursement, the highest ever demands by the consumer for perfect medical care, and increasingly stringent requirements for the presence and involvement of attending faculty in patient care (for both medical-legal, and 80-hour work week reasons), the overall result makes for a barely tenable situation for the physician-scientist."

From The Relationship Between Surgeon and Basic Scientist by T. Carrel $^{20}$ :

"The rapid pace of contemporary research makes it difficult if not impossible for one person to be an intense clinician and intense researcher at the same time. Is it appropriate for the physician-scientist to see the patient in the morning and to clone the genes in the afternoon? Probably not."

From The Cardiothoracic Surgeon and the Basic Scientist by Jarle Vagge ${ }^{21}$ :

"Even if we may be next to God in the operating room, there is no guarantee that we are anything, but at best 
eager amateurs in engineering, in cell biology, and in basic science in general."

From Training the Contemporary Surgeon-Scientist by Wan and co-workers $^{22}$ :

"The old standard of triple-threat surgeon scientists who could seamlessly move between the clinic/operating room, laboratory, and classroom has increasingly fallen by the wayside in today's environment of universal and managed health care."

From Some of the 'Do's' and 'Do-Not's' in Clinical Investigation by Fuller Albright ${ }^{23}$ :

The clinical investigator is as one "trying to ride two horses - attempting to be an investigator and a clinician at one and the same time."

From Surgeon Scientist by Joseph E. Murray (plastic/transplant surgeon and Nobel laureate) ${ }^{24}$ :

"Conceptually, the surgeon and bench scientist differ in three ways.

1. The scientist knows that he does not know, whereas the clinical surgeon treating patients is expected to know.

2. The scientist can wait for all the data to become available, whereas the surgeon must make a decision based on available data.

3. The scientist deals with mass data, whereas the surgeon deals with an individual patient.

Acknowledging these differences, is it possible for a surgeon, or any clinician, to be a scientist? The answer, of course, is yes. It is a difficult role to assume, but it is absolutely essential for medical progress that dedicated clinical surgeons and scientists understand and work with scientists of other basic disciplines. It is a simple fact that basic scientists cannot be surgeons, so it is essential that surgeons be scientists."

[Disclosure: the author of this editorial met Dr. Murray in 1990 at Children's Hospital/Harvard Medical School in Boston while doing an MRC fellowship with surgeon-scientist Dr. Judah Folkman ${ }^{24}$. Dr. Murray had just been awarded the Nobel Prize in Physiology and Medicine for his work on renal transplantation. $\mathrm{He}$ is one of only nine surgeons (and the last) to receive the Nobel Prize ${ }^{9}$.]

"Discussion": A number of themes emerged from the reviewed articles. These will be discussed briefly.

Yes, there IS a role for the surgeon-scientist!: The majority of articles generally favour the preservation of the surgeon scientist ${ }^{5,8,24-32}$. Of course a number of these articles are written by successful surgeon-scientists and academic surgeons who practiced in a less restrictive $\mathrm{era}^{33}$. These articles argue that despite contemporary challenges there is a need for surgeons to continue "tending the bridge" (see "results" section above ${ }^{18,19}$ ) i.e. that surgeons are in the unique position to care for patients, identify areas that need better understanding, and then go on to initiate and perform the research themselves to gain that understanding. However, most articles acknowledge that there are many challenges. These include: 1. Lack of interest in research at the medical school level ${ }^{15,25} ; 2$. Difficulties in nurturing research involvement during surgical residency training, (due to lack of interest, financial considerations and work hour restrictions, etc. $)^{34-40} ; 3$. Mentorship challenges at the resident and junior faculty level ${ }^{41} ; 4$. Difficulty in obtaining grant support as an individual researcher ${ }^{25} ; 5$. Global decreases in funding for biomedical research at government and industry levels ${ }^{7,25,42-44}$; 6 . Actual inability to follow through on clinical insights at the laboratory level due to the pace at which science is advancing (Paralyzed Academic Investigator's Disease Syndrome or PAIDS $)^{45-48} ; 7$. Changing expectations of hospitals and health care providers ${ }^{49,50} ; 8$. Frustration with the "carnival of science" ${ }^{51}$; 9. Perceived lack of reward ${ }^{14} ; 10$. Overburdening with administrative and teaching duties ${ }^{23,25,52}$.

Really, IS there a role for the surgeon-scientist?: Interestingly, notwithstanding the excerpts in the "results" section above, very few articles in the literature, if any, question the desirability of preserving the surgeon-scientist. A number of $\operatorname{articles}^{5,20,24,53}$, including the paper by Girgis in this journal ${ }^{1}$, suggest that collaboration between surgeons and scientists may be a more feasible and effective way of actually producing meaningful research. Indeed a number of the top-cited articles in neurosurgery journals are the product of collaborative efforts ${ }^{54,55}$. What the paper by Girgis also draws attention to is something that is infrequently addressed in the literature: the perception of what it is to be an academic surgeon. The traditional job description of an academic surgeon includes somewhat equal measures of ${ }^{56,57}: 1$. A role model clinician expected to deliver the most advanced, life-saving surgical care to the most complicated patients; 2. A teacher expected to design and implement programs to teach the art of surgery to both surgeon and nonsurgeon trainees, including basic and advanced skills; 3. A researcher expected to conduct novel basic or clinical research with evidence of success; 4. A mentor expected to provide guidance to students, residents, fellows, and junior faculty; 5. An administrator expected to progressively increase administrative activities in the department, medical school, and health system with minimal reduction in other responsibilities; and 6. A promoter of academic surgery nationally and internationally by being active in surgical societies and symposia. Though excellence in all of the above is something the academic surgeon might strive for, the article by Girgis would suggest neurosurgeons and neurosurgery residents in Canada value clinical skill and patient care above all ... but is that enough?

"Conclusions": So, ... a role for the surgeon-scientist? You weigh the "evidence" (ideally after reading the references more thoroughly, if you have time between the OR, lab and classroom!). You decide.
Joseph F. Megyesi
London, Ontario, Canada 


\section{REFERENCES}

1. Girgis F. Feasibility of a dual neurosurgeon-scientist career in Canada: a survey study. Can J Neurol Sci. 2013;40(4):504-11.

2. Toledo-Pereyra LH. William Beaumont: First American surgeon scientist and father of gastric physiology. J Invest Surg. 2003;16: 55-6.

3. Feindel W. Theodore Brown Rasmussen (1910-2002): epilepsy surgeon, scientist, and teacher. J Neurosurg. 2003;98:631-7.

4. Monaco AP. Joseph Edward Murray, M.D., 1919-2012: pioneering transplant and reconstructive plastic surgeon and scientist, nobel laureate, humanitarian - an appreciation. Transplantation. 2013; 95:903-7.

5. Goldstein JL, Brown MS. The clinical investigator: bewitched, bothered, and bewildered - but still beloved. J Clin Invest. 1997; 99:2803-12.

6. Goldstein JL, Brown MS. A golden era of nobel laureates. Science. 2012;338:1033-4

7. Nathan DG, Varmus HE. The National Institutes of Health and Clinical Research: a progress report. Nat Med. 2000;11:1201-4.

8. Gittes GK. The surgeon-scientist in a new biomedical research era. Surgery. 2006;140:123-31.

9. Cosimi AB. Surgeons and the Nobel Prize. Arch Surg. 2006;141: 340-8.

10. Wyngaarden JB. The clinical investigator as an endangered species. N Engl J Med. 1979;301:1254-9.

11. Bloom FE. Science as a way of life: perplexities of a physicianscientist. Science. 2003;300:1680-5.

12. Varki AJ. Disappearing physician-scientists. Science. 1999;283: 791-2.

13. Gershon D. Improving the plight of the physician-scientist in the US. Nature. 1999;402:215-16.

14. Malakoff D. The many ways of making academic research pay off. Science. 2013;339:750-3

15. Guelich JM, Singer BH, Castro MC, Rosenberg LE. A gender gap in the next generation of physician-scientists: medical student interest and participation in research. J Invest Med. 2002;50: 412-18.

16. Ko CY, Whang EE, Longmire WP Jr, McFadden DW. Improving the surgeon's participation in research: is it a problem of training or priority? J Surg Res. 2000;91:5-8.

17. Ley TJ, Rosenberg LE. The physician-scientist career pipeline in 2005. Build it, and they will come. JAMA. 2005;294:1343-51.

18. Moore FD. The university in American surgery. Surgery. 1958;44: $1-10$.

19. Chiu RCJ. The challenge of "tending the bridge". Ann Thorac Surg. 2008;85:1149-50.

20. Carrel T. The relationship between surgeon and basic scientist. Transpl Immunol. 2002;9:331-7.

21. Vaage $\mathbf{J}$. The cardiothoracic surgeon and the basic scientist. Eur $\mathbf{J}$ Cardiothorac Surg. 2004;26:237-8.

22. Wan DC, Wang KC, Longaker MT. Training the contemporary surgeon-scientist. Plast Reconstr Surg. 2012;129:1023-5.

23. Albright F. Some of the "do's" and "do-not's" in clinical investigation. J Clin Invest. 1994;23:921-6.

24. Murray JE. Surgeon scientist. World J Surg. 2000;24:757-8.

25. Wells SA. The surgical scientist. Ann Surg. 1996;224:239-54.

26. Rosenberg LE. Physician-scientists - endangered and essential. Science. 1999;283:331-2.

27. Rosenberg LE. The physician-scientist: an essential - and fragile link in the medical research chain. J Clin Invest. 1999;103: $1621-6$.

28. Vollmar B, Menger MD. Does experimental surgery still exist? Chirurg. 2010;81:3237.

29. Schaeffer AJ. The surgeon-scientist: a challenge that can be met. J Urol. 2006;176:9.

30. Gruber PJ. Idealism versus reality: the modern surgeon-scientist. Ann Thorac Surg. 2008;85:1151-2.

31. Gill GN. The end of the physician-scientist? Am Schol. 1984;53: 353-68

32. Hurwitz SR, Buckwalter JA. The orthopaedic surgeon scientist: an endangered species? J Orthop Res. 1999;17:155-6.
33. Spodick DH. Numerators without denominators. There is no FDA for the surgeon. JAMA. 1975;232:35-6.

34. Scardino PT. Training of a surgeon-scientist. Urol Oncol. 2009;27: $117-29$

35. Dunn JC, Lai EC, Brooks CM, Stabile BE, Fonkalsrud EW. The outcome of research training during surgical residency. J Pediatr Surg. 1998;33:362-4.

36. Skenderis BS II, Rustum YM, Petrelli NJ. Basic science research in postgraduate surgical training. Difficulties encountered by clinical scientists. J Cancer Educ. 1997;12:245-8.

37. Sklar DP. Faculty supervision of residents - creating important moments of magic. Acad Med. 2013;88:431-3.

38. Hutter MM, Kellogg KC, Ferguson CM, Abbott WM, Warshaw AL. The impact of the 80-hour resident workweek on surgical residents and attending surgeons. Ann Surg. 2006;243:864-71.

39. Menger MD, Schilling MK, Schafers H-J, Pohlemann T, Laschke MW. How to ensure the survival of the surgeon-scientist? The Homburg Program. Langenbecks Arch Surg. 2012;397:619-22.

40. Boss GR. Is clinical subspecialty training necessary to become a physician-scientist? J Invest Med. 1994;44:136-8.

41. Palepu A, Friedman RH, Barnett RC, et al. Junior faculty member's mentoring relationships and their professional development in US medical schools. Acad Med. 1998;73:318-23.

42. Iglehart JK. Support for academic medical centers. N Engl J Med. 1999;341:299-304.

43. Moy E, Griner PF, Challoner DR, Perry DR. Distribution of research awards from the National Institutes of Health among medical schools. N Engl J Med. 2000;342:250-5.

44. Malakoff D. NIH prays for a soft landing after its doubling ride ends. Science. 2001;292:1992-5.

45. Goldstein JL. On the origin and prevention of PAIDS (Paralyzed Academic Investigator's Disease Syndrome). J Clin Invest. 1986:78:848-54.

46. Bell JL. Clinical research is dead; long live clinical research. Nat Med. 1999;5:477-8.

47. Messina LM. The role of the surgeon scientist in gene therapy. J Invest Surg. 1995;8:335-6.

48. Kitto S, Petrovic A, Gruen RL, Smith JA. Evidence based medicine training and implementation in surgery: the role of surgical culture. J Eval Clin Pract. 2011;17:819-26.

49. Kuttner R. Managed care and medical education. N Engl J Med. 1999;341:1092-6.

50. Swales JD. Science in a health service. Lancet. 1997;349:1319-21.

51. Horton R. The unmasked carnival of science. Lancet. 1998; 351:688-9.

52. Dragstedt CA. Who killed Cock Robin? Perspect Biol Med. 1962; 5:364-76

53. Henke PK. Collaboration based on the clinical model can help grow the physician-scientist. Am J Surg. 2003;185:42-4.

54. Ponce FA, Lozano AM. Highly cited works in neurosurgery. Part I: the 100 top-cited papers in neurosurgical journals. J Neurosurg. 2010;112:223-32.

55. Ponce FA, Lozano AM. Highly cited works in neurosurgery. Part II: the citation classics. J Neurosurg. 2010;112:233-46.

56. Billiar TR. Routine complexity. Surgery. 2001;130:123-32.

57. de Leval MR. From art to science: a fairy tale? The future of academic surgery. Ann Thorac Surg. 2001;72:9-12. 